\title{
BMJ Open Health and wellbeing of people with intellectual disability in New South Wales, Australia: a data linkage cohort
}

\author{
Simone Reppermund, ${ }^{1,2}$ Theresa Heintze, ${ }^{1}$ Preeyaporn Srasuebkul, ${ }^{1}$ \\ Rebecca Reeve, ${ }^{3}$ Kimberlie Dean, ${ }^{4,5}$ Melinda Smith, ${ }^{5}$ Eric Emerson, ${ }^{6}$ \\ Phillip Snoyman, ${ }^{7}$ Eileen Baldry, ${ }^{8}$ Leanne Dowse, ${ }^{3}$ Tracey Szanto, ${ }^{9}$ \\ Grant Sara (D) , ${ }^{10,11}$ Tony Florio, ${ }^{1}$ Anina Johnson, ${ }^{12}$ Melissa Clements, ${ }^{13}$ \\ Kathryn McKenzie, ${ }^{14}$ Julian Trollor (D) ${ }^{1,2}$
}

To cite: Reppermund S, Heintze T, Srasuebkul P, et al. Health and wellbeing of people with intellectual disability in New South Wales, Australia: a data linkage cohort. BMJ Open 2019;9:e031624. doi:10.1136/ bmjopen-2019-031624

- Prepublication history and additional material for this paper are available online. To view these files, please visit the journal online (http://dx.doi. org/10.1136/bmjopen-2019031624).

Received 13 May 2019 Revised 25 August 2019 Accepted 03 September 2019

Check for updates

(c) Author(s) (or their employer(s)) 2019. Re-use permitted under CC BY-NC. No commercial re-use. See rights and permissions. Published by BMJ.

For numbered affiliations see end of article.

Correspondence to Dr Simone Reppermund; s.reppermund@unsw.edu.au

\section{ABSTRACT}

Purpose People with intellectual disability (ID) experience high rates of physical and mental health problems, while access to appropriate healthcare is often poor. This cohort was established to develop an epidemiological profile related to the health, health service use, disability services, mortality and corrective services records of people with ID. Participants The cohort contains 92542 people with ID (40\% females) with a median age of 23 years (IQR: $12-43$ years) and 2004475 people with a neuropsychiatric or developmental disorder diagnosis (50\% females) with a median age of 51 years (IQR: 29-73 years) from New South Wales, Australia. The whole sample contains records for 2097017 individuals with most data sets spanning financial years 1 July 2001 to 30 June 2016. A wide range of data from linked population data sets are included in the areas of disability, health, corrective services and targeted specialist support services in public schools, Public Guardian and Ombudsman services.

Findings to date This study includes one of the largest cohorts of people with ID internationally. Our data have shown that the presence of ID is significantly associated with emergency department presentations and psychiatric readmissions after the first psychiatric admission based on a subcohort of people with a psychiatric admission. Adults with ID experience premature mortality and overrepresentation of potentially avoidable deaths compared with the general population.

Future plans Within the health service system, we will examine different components, that is, inpatient, emergency adult services, children and younger people services and costs associated with healthcare as well as mortality, cause and predictors of death. The neuropsychiatric and developmental disorders comparison cohort allows comparisons of the physical health, mental health and service use profiles of people with ID and those with other neuropsychiatric disorders.

\section{INTRODUCTION}

Intellectual disability (ID) is a neurodevelopmental disorder characterised by impairments in intellectual and adaptive functioning (activities of daily living such as communication and independent living) with an onset
Strengths and limitations of this study

- This study links data across multiple health and human services data sets to build one of the largest cohort of people with intellectual disability (ID) internationally and a large neuropsychiatric and developmental disorders comparison cohort.

- The cohort enables the analysis of patterns of service use across multiple different service systems, giving valuable information about physical health, mental health and service use profiles of people with ID and those with other neuropsychiatric and developmental disorders.

- The emerging findings from the cohort have played a key role in informing the development of improved service system responses for people with ID.

- As with most administrative data sets, lack of detailed clinical information prevents the inclusion of some valuable information relating to severity of disability or measures of adaptive behaviour in our analysis models.

- Since the cohort only includes people with ID who have received disability services or who have an ID diagnosis in one of the included data sets, it is likely that people with milder ID are under-represented.

during childhood. ${ }^{1}$ The International Statistical Classification of Diseases and Related Health Problems 11th revision (ICD-11) classifies ID as disorders of intellectual development categorised into mild (intellectual functioning and adaptive behaviour approximately two to three SD below the mean), moderate (approximately three to four SD below the mean), severe and profound (both approximately four or more SD below the mean) disorders. ${ }^{2}$ People with ID represent about $1 \%$ of the population. ${ }^{3}{ }^{4}$ Compared with the general population, people with ID have higher rates of poor physical and mental health, ${ }^{5}$ lower life expectancy and a relatively high rate of potentially avoidable deaths. ${ }^{6}$ 
They also experience multiple barriers to accessing appropriate health services ${ }^{7}$ and are over-represented in the criminal justice system. ${ }^{8}$ Specific consideration of people with ID in Australian mental health policy is missing. This is a significant exclusion, given the very high rate of mental illness of up to $50 \%,{ }^{59}$ reflecting and contributing to major barriers in access to mental health services and treatments. ${ }^{1011}$

We assembled a longitudinal cohort data set with the overarching aim of providing an epidemiological profile of the health (including mental health), health service use, mortality, corrective services and other service system contacts of people with ID in New South Wales (NSW), Australia. Currently, these individual data sets are not routinely linked, making it difficult to develop a comprehensive understanding of the physical health and mental healthcare needs of people with ID. Such an understanding is essential to underpin efforts to improve the health of people with ID. Previous findings from our group related to mortality, emergency department presentations and readmission after index psychiatric admission using linked data ${ }^{61213}$ were based on a smaller cohort, shorter timeframe and fewer linked data sets. ${ }^{14}$

The project is supported by a National Health and Medical Research Council Australia Partnerships for Better Health grant (ID: APP1056128; Title: Improving the Mental Health Outcomes of People with an Intellectual Disability) with monetary and in-kind contributions from collaborating partner organisations (see Acknowledgements for a list of all partner organisations).

\section{COHORT DESCRIPTION}

The historical cohort study comprises 92542 people identified as having ID who received disability services, ambulatory mental health services, targeted specialist support services in public schools, Corrective Services NSW, NSW Ombudsman and NSW Public Guardian services and/or were admitted to hospital and presented to emergency departments in NSW between 1 January 1994 and 30 June 2016. Administrative data sets were linked at the person level to allow analysis of the pattern and determinants of service use in people with ID.

All people identified as having ID either had a diagnosis of ID based on the Diagnostic and Statistical Manual of Mental Disorders (DSM) IV or had an ICD-10 code for ID in their health record. Twenty-nine per cent of the ID cohort had only a DSM IV diagnosis of ID, $22 \%$ had only an ICD-10 diagnosis and 49\% had diagnoses of ID from both sources. Individuals can have a DSM IV as well as an ICD-10 diagnosis of ID because they may appear in more than one data set. For example, the DSM IV diagnostic classification system was used in the disability services minimum data set (DS-MDS) and in the Mental Health Ambulatory data set, whereas ICD-10 codes were used in the hospital admission data set. A cohort of people with neuropsychiatric and developmental disorders but without ID was constructed from the data set for the purposes of comparison. This comparison cohort (referred to as NC cohort henceforth) includes 2004 475 people with either mental or behavioural disorders (ICD-10 F codes, except F70-F98); nerve, nerve root and plexus disorders (ICD-10 G codes); congenital malformations; deformation and chromosomal abnormalities (ICD-10 Q codes, except Q86-Q99) or those with selfharm diagnoses (ICD10×6-X8, Z86.5) who appeared in ambulatory mental health services data between 1 January 2001 and 31 December 2015 or were admitted to an NSW hospital between 1 July 2001 and 30 June 2016 or who appeared in the EDDC between 1 July 2005 and 30 June 2016. The ICD-9 or Systematised Nomenclature of Medicine (SNOMED; a structured clinical terminology used in electronic health records) codes equivalent to the included ICD-10 codes were used if required. The NC cohort is relevant to the new Australian disability landscape as these individuals, like those in the ID cohort, may be eligible to receive services under the National Disability Insurance Scheme due to the psychosocial, cognitive or physical disabilities associated with their conditions. People with ID frequently have comorbid neuropsychiatric and developmental disorders. Consequently, a comparison group with these conditions but without ID helps to disentangle outcomes associated with ID from other conditions.

For both cohorts, data are available for multiple years. The linked data set contains data for the time periods 1 July 2005 to 30 June 2015 for disability services, 1 January 2001 to 30 June 2016 for health services, 1 January 1985 to 31 March 2016 for mortality, 1 January 1994 to 31 May 2016 for corrective services and 1 January 1994 to 30 April 2016 for other services including disability support in public schools, NSW Public Guardian and NSW Ombudsman services. The ID and NC cohorts together contain 2097403 individuals for the financial years 1 July 2001 to 30 June 2016 and 2097017 individuals for the financial years 1 July 2001 to 30 June 2015 .

Figure 1 gives an overview of all data sets used for the cohort formation and the number of individuals in each of the cohorts within each data set based on financial years 1 July 2001 to 30 June 2015 for better comparability.

Linkage of the data sets was performed by the NSW Centre for Health Record Linkage (CHeReL). The CHeReL links health-related data in NSW in accordance with State and Commonwealth ethical, legal, privacy and confidentiality requirements. To protect the identities and confidentiality of individuals while retaining the ability to link each person's data across multiple data sets, each person is represented by a unique project-specific numerical identifier assigned by the CHeReL.

The majority of the ID cohort were identified from health services data sets, followed by the disability services data set (71\% and 64\%, respectively; note that individuals can appear in both service systems). Three per cent stem from Corrective Services NSW and 29\% from the other data sets $(24 \%$ from targeted specialist support services in public schools, $4 \%$ from NSW Public Guardian and 1\% 


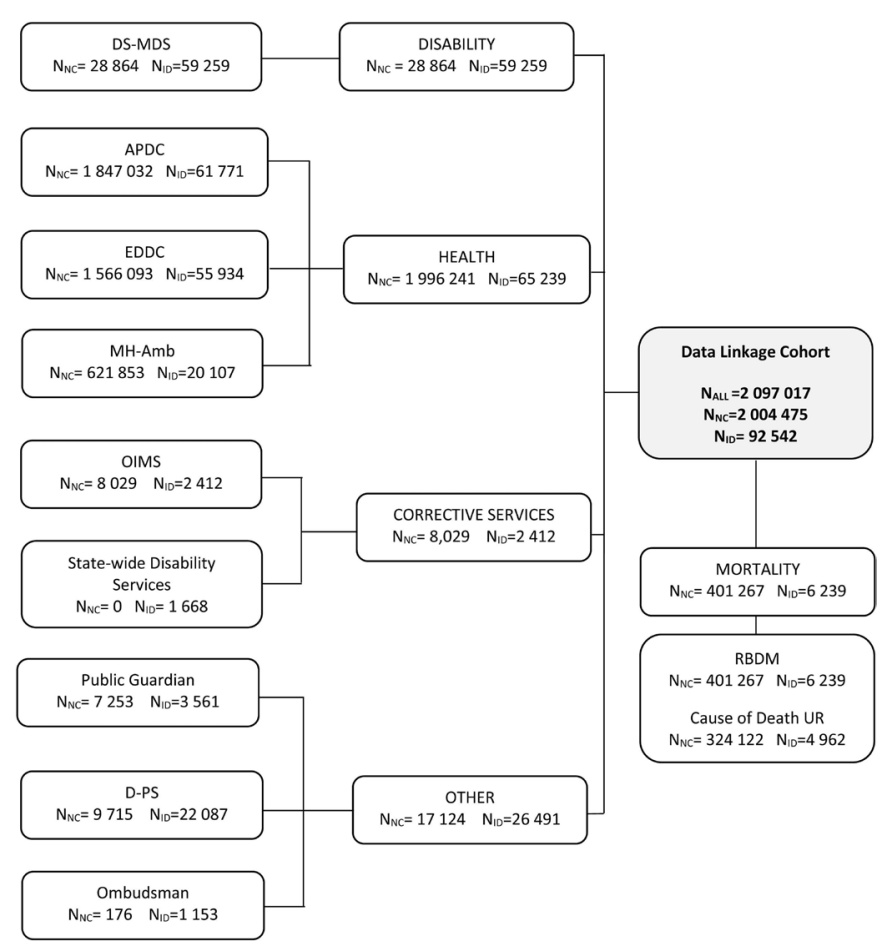

Figure 1 Numbers of individuals in the different data sets. APDC, Admitted Patient Data Collection; D-PS, Disability in Public Schools data set; DS-MDS, Disability Services Minimum Data Set; EDDC, Emergency Department Data Collection; MH-Amb, Mental Health Ambulatory data set; $\mathrm{N}_{\mathrm{ID}}$, people with intellectual disability; $\mathrm{N}_{\mathrm{NC}}$, neuropsychiatric and developmental disorders comparison cohort; OIMS, Offender Integrated Management System; RBDM, Registry of Birth, Death and Marriages; UR, Unit Record.

from NSW Ombudsman). The cohort with ID represents $1.13 \%$ of the NSW population in calendar year 2015. NSW is the most populous state in Australia with 7.67 million people in 2015 , which is $32 \%$ of the Australian population. ${ }^{15}$ Table 1 shows the demographic characteristics of individuals with ID and the NC cohort, and table 2 shows the demographic characteristics of individuals in both cohorts based on the different source data sets of disability services, health services, mortality and corrective services. As in figure 1, we present data from financial years 1 July 2001 to 30 June 2015 , so that data from the various data sets are more comparable.

A higher proportion of the ID cohort are children and youth compared with the NC cohort, whereas a higher percentage of the NC cohort are over the age of 65 years. Those in the ID cohort are more likely to be male. A larger percentage of $\mathrm{NC}$ cohort live in major cities, but overall the proportion of the cohorts in the remoteness categories is comparable. A higher proportion of people with ID is represented in the most disadvantaged category of the relative socioeconomic disadvantage index, with a higher proportion of the NC cohort in the least disadvantaged category. The relative socioeconomic disadvantage index ranks areas in Australia according to relative socioeconomic disadvantage based on income, education, employment, occupation, housing and other miscellaneous indicators of relative disadvantage. ${ }^{16}$ The associations between the prevalence of ID and both male gender and socioeconomic disadvantage are well established in the epidemiological literature. ${ }^{4}$

The broad categories of data available for individuals in this large linked data set are disability, health, mortality, corrective services and other services related to targeted specialist support services in public schools, reviewable deaths (NSW Ombudsman) and supported decision making (NSW Public Guardian). In general, the data reflect contact with the relevant services, capturing variables including the timing, the reason and the outcome of contact.

\section{Disability}

The DS-MDS contains DSM IV diagnoses related to aetiology of disability and includes information about all people of all ages who received a disability service in NSW for the financial years 1 July 2005 to 30 June 2015, including the type of disability and services provided. The main services include accommodation, community support, community access and respite. Eligible for disability services were Australian citizens or permanent residents under the age of 65 years who met disability requirements. Disability requirements include that the impairment is likely to be permanent, the impairment affects the person's capacity for social and economic participation, the impairment substantially reduces the ability to take part effectively in activities (ie, communication, social interaction, learning, mobility, self-care or self-management) or perform tasks or actions unless the person has assistance from other people on most days, or the person has assistive technology, equipment (other than common items such as glasses) or they cannot take part effectively even with assistance or aids and equipment.

\section{Health}

The Admitted Patient Data Collection (APDC) contains admissions to NSW public, private and multipurpose day hospitals for the financial years 1 July 2001 to 30 June 2016. It records dates of admission and separation for each episode of care, up to 50 diagnoses relevant to each episode of care, the source of referral, separation mode and procedures, based on ICD-10 Australian version. It also contains the Australian Diagnosis Related Group and type of admissions, which allows for the estimation for the cost of care.

The Emergency Department Data Collection (EDDC) contains presentations to most emergency departments in NSW public hospitals for the financial years 1 July 2005 to 30 June 2016. Records include dates and times of presentation and discharge, reason for presentation, triage category and outcome of the presentation (discharge, transfer or death).

The Mental Health Ambulatory (MH-Amb) data set contains information on NSW specialist ambulatory mental health services for the financial years 1 January 2001 to 31 December 2015. Ambulatory mental health services are generally those offered to non-admitted patients. It may include mental health day programme, 
Table 1 Demographics of individuals with and without ID

\begin{tabular}{|c|c|c|c|}
\hline & ID & NC & All \\
\hline & $\mathbf{N}(\%)$ & $\mathbf{N}(\%)$ & N (\%) \\
\hline \multicolumn{4}{|l|}{ Age $^{*}$ (years) } \\
\hline $0-17$ & 36336 (39.3) & 2790694 (14.0) & $316030(15.1)$ \\
\hline $18-24$ & $13115(14.2)$ & 129595 (6.5) & $142710(6.8)$ \\
\hline $25-44$ & 21459 (23.2) & $451100(22.5)$ & $472559(22.5)$ \\
\hline $45-64$ & $15491(16.7)$ & 452322 (22.6) & $467813(22.3)$ \\
\hline $65+$ & 6004 (6.5) & 682924 (34.1) & 688928 (32.9) \\
\hline Invalid & $137(0.2)$ & $8840(0.4)$ & $8977(0.5)$ \\
\hline Total & $92542(100.0)$ & $2004475(100.0)$ & 2097017 (100.0) \\
\hline \multicolumn{4}{|l|}{ Sex } \\
\hline Male & $55894(60.4)$ & $1002456(50.0)$ & $1058350(50.5)$ \\
\hline Female & 36572 (39.5) & 995711 (49.7) & $1032283(49.2)$ \\
\hline Other/linvalid & $76(0.1)$ & $6308(0.3)$ & $6384(0.3)$ \\
\hline Total & $92542(100)$ & 2004475 (100) & $2097017(100)$ \\
\hline \multicolumn{4}{|l|}{ Remoteness } \\
\hline Major cities & 58542 (63.3) & 1381714 (68.9) & $1440256(68.7)$ \\
\hline Inner regional & 20975 (22.7) & $414975(20.7)$ & $435950(20.8)$ \\
\hline Outer regional & 8259 (8.9) & $129606(6.5)$ & 137865 (6.6) \\
\hline Remote & $436(0.5)$ & $8370(0.4)$ & $8806(0.4)$ \\
\hline Very remote & $449(0.5)$ & $3522(0.2)$ & $3971(0.2)$ \\
\hline Invalid & $3881(4.2)$ & $66288(3.3)$ & 70169 (3.3) \\
\hline Total & $92542(100)$ & 2004475 (100) & 2097017 (100) \\
\hline \multicolumn{4}{|c|}{ Index of relative socioeconomic disadvantage } \\
\hline $\begin{array}{l}\text { First quintile (most } \\
\text { disadvantaged) }\end{array}$ & $20661(22.3)$ & $419046(20.9)$ & $439707(21.0)$ \\
\hline Second quintile & $17268(18.7)$ & 372707 (18.6) & $389268(18.6)$ \\
\hline Third quintile & $18964(20.5)$ & $383626(19.1)$ & $402590(19.2)$ \\
\hline Fourth quintile & $16581(17.9)$ & $345579(17.2)$ & $362157(17.3)$ \\
\hline $\begin{array}{l}\text { Fifth quintile (least } \\
\text { disadvantaged) }\end{array}$ & $13589(14.7)$ & $416212(20.8)$ & 429801 (20.5) \\
\hline Invalid & $5479(5.9)$ & $67308(3.4)$ & $72787(3.5)$ \\
\hline Total & $92542(100)$ & $2004475(100)$ & $2097017(100)$ \\
\hline
\end{tabular}

${ }^{*}$ Age calculated at the end of financial year 2014/2015.

ID, intellectual disability; NC, neuropsychiatric and developmental disorders comparison cohort.

psychiatric outpatients and outreach services (eg, home visits). MH-Amb does not include data on mental health services provided in primary care or private office-based psychology and psychiatry services.

\section{Mortality}

The Registry of Births, Deaths and Marriages (RBDM) contains information on date and causes of deaths in NSW for the period of 1 January 1994 to 31 March 2016. The NSW Cause of Death Unit Record contains coded causes of deaths in NSW for the financial years 1 January 1985 to 31 December 2013.

\section{Corrective services}

The Corrective Services NSW Disability Services data set contains information on recipients of disability services during custody, along with conviction history for the time period 1 January 2001 to 31 May 2016. The Offender Integrated Management System contains information relating to prisoner location and transfer history, classification, security and self-harm behaviour in custody for the period of 1 January 1994 to 31 May 2016.

\section{Other}

The disability programs in public schools (D-PS) data set contains information on specialist disability services 
Table 2 Demographics of individuals with and without ID in the different data sets of disability services, health services, mortality and criminal justice

\begin{tabular}{|c|c|c|c|c|c|c|c|c|}
\hline & \multicolumn{2}{|c|}{$\begin{array}{l}\text { Disability services ID NC } \\
(n=59 \text { 259) }(n=28 \text { 864) }\end{array}$} & \multicolumn{2}{|c|}{$\begin{array}{l}\text { Health services ID NC } \\
(n=65239)(n=1996241)\end{array}$} & \multicolumn{2}{|c|}{$\begin{array}{l}\text { Mortality ID NC } \\
(n=6239)(n=401267)\end{array}$} & \multicolumn{2}{|c|}{$\begin{array}{l}\text { Corrective services ID NC } \\
(n=2412)(n=8029)\end{array}$} \\
\hline & N (\%) & $\mathrm{N}(\%)$ & N (\%) & N (\%) & N (\%) & N (\%) & N (\%) & N (\%) \\
\hline $0-17$ & 20742 (35.0) & $16362(56.7)$ & $29435(45.12)$ & 273055 (13.7) & $943(15.1)$ & $2454(0.6)$ & $\dagger$ & $\dagger$ \\
\hline $18-24$ & $10613(17.9)$ & $2488(8.6)$ & 7413 (11.36) & $128531(6.4)$ & $249(4.0)$ & $1549(0.4)$ & 432 (17.9) & $753(7.1)$ \\
\hline $25-44$ & $15143(25.6)$ & $3103(10.8)$ & $13045(20.0)$ & 450677 (22.6) & $897(14.4)$ & $11912(3.0)$ & 1518 (62.9) & $4530(55.2)$ \\
\hline $65+$ & $2534(4.3)$ & $1910(6.6)$ & $4809(7.4)$ & $682901(34.2)$ & 2071 (33.2) & 334495 (83.4) & $34(1.4)$ & $462(6.7)$ \\
\hline Invalid & $6(<0.1)$ & $3(<0.1)$ & $133(0.2)$ & $8839(0.4)$ & 114 (1.8) & $3243(0.8)$ & $0(0.0)$ & $0(0.0)$ \\
\hline \multicolumn{9}{|l|}{ Sex } \\
\hline Male & $36293(61.2)$ & $19386(67.2)$ & $39794(61.0)$ & 995973 (49.9) & 3480 (55.8) & $201440(50.2)$ & 2167 (89.8) & $7274(90.6)$ \\
\hline Female & 22941 (38.7) & 9463 (32.8) & 25395 (38.9) & 993975 (49.8) & 2759 (44.2) & 199817 (49.8) & 245 (10.2) & 755 (9.4) \\
\hline Inner regional & 14265 (24.1) & 7135 (24.7) & $14858(22.8)$ & $413220(20.7)$ & $1359(21.8)$ & $86773(21.6)$ & $647(26.8)$ & $2031(25.3)$ \\
\hline Outer regional & 5865 (9.9) & 2674 (9.3) & $5728(8.8)$ & $128963(6.5)$ & $489(7.8)$ & $27567(6.9)$ & $235(9.7)$ & 719 (9.0) \\
\hline Remote & $228(0.4)$ & $105(0.4)$ & $319(0.5)$ & $8361(0.4)$ & $24(0.4)$ & $1507(0.4)$ & $20(0.8)$ & $102(1.3)$ \\
\hline Very remote & $314(0.5)$ & $88(0.3)$ & $341(0.5)$ & $3511(0.2)$ & $24(0.4)$ & $522(0.1)$ & $30(1.2)$ & $76(1.0)$ \\
\hline Invalid & $1786(3.0)$ & 1205 (4.2) & 969 (1.5) & $64550(3.2)$ & $46(0.7)$ & $2673(0.7)$ & $68(2.8)$ & $88(1.1)$ \\
\hline \multicolumn{9}{|c|}{ Socioeconomic disadvantage } \\
\hline First quintileł & $11411(19.3)$ & $5141(17.8)$ & $15876(24.3)$ & 417907 (20.9) & $1384(22.2)$ & $89872(22.4)$ & $709(29.4)$ & $2400(29.9)$ \\
\hline Second quintile & $10544(17.8)$ & $4798(16.6)$ & $12812(19.6)$ & $371499(18.6)$ & $1326(21.3)$ & $79612(19.8)$ & $537(22.2)$ & $1968(24.5)$ \\
\hline Third quintile & $12777(21.6)$ & $5987(20.7)$ & $13507(20.7)$ & 382224 (19.2) & $1304(20.9)$ & $80592(20.1)$ & $548(22.7)$ & $1896(23.6)$ \\
\hline
\end{tabular}

*Age calculated at the end of financial year 2014/2015.

†Due to very small numbers in the 0 - to 17-year age group, numbers have been combined with the 18- to 24-year age group.

łIndex of relative socioeconomic disadvantage, most disadvantaged.

§Index of relative socioeconomic disadvantage, least disadvantaged.

ID, intellectual disability; NC, neuropsychiatric and developmental disorders comparison cohort.

delivered in NSW public schools for the period of 1 January 2011 to 30 June 2015. These services ensure that the specific needs of students with disability and additional learning and support needs are met and may include additional staff in the classroom and support for professional learning for teachers. The NSW Public Guardian data set contains information on people with disability who received a Public Guardian service for decision making assistance in the areas of health and lifestyle. Records include ID diagnoses and offending history for the period 1 January 1994 to 30 April 2016. The NSW Ombudsman data set contains information on reviewable deaths in residential care. Records include ID diagnosis, other disabilities, causes and place of death for the period 1 December 2002 to 31 December 2015.

A full list of the variables in all data sets is presented in online supplementary file 1 .

\section{Patient and public involvement}

The cohort is part of a larger project using a multipronged approach to guide the development of targeted, appropriate services for people with ID. A consumer reference group including people with ID and their carers/support person oversees and provides advice on the research and dissemination for the life of the project. The consumer reference group ensures that priorities of people with ID and their carers/ support persons are considered throughout the project and that the research process is accountable to people with ID and their carers/support persons.

\section{FINDINGS TO DATE}

Table 2 shows the demographic characteristics of the ID and NC cohorts within each category of data from financial years 1 July 2001 to 30 June 2015. 


\section{Disability services}

In both cohorts, individuals were most likely to receive disability services in childhood (ages $0-17$ years) but a higher proportion of the NC cohort were child recipients $(57 \%)$ compared with the ID cohort $(35 \%)$. People with ID were more likely to receive disability services in adulthood (ages 18-44 years) than were those in the NC cohort, whereas a higher proportion of the NC cohort received services during old age (65 years and over). Although males in both cohorts were more likely to receive disability services than females, there was a higher proportion of males receiving services in the NC cohort compared with the ID cohort ( $67 \%$ vs $61 \%$ ). Subsequently, a higher percentage of females with ID received disability services compared with females in the NC cohort $(39 \%$ vs 33\%). Although a higher proportion of people with ID lived in very remote areas, the proportions of both cohorts were very similar over the remoteness categories. People with ID were more likely to live in a disadvantaged neighbourhood compared with those in the NC cohort.

\section{Health}

Individuals with ID in the health data sets were more likely to be younger and male than those in the NC cohort. The largest proportion of people with ID in the health data sets were children $(0-17$ years; $45 \%)$ compared with $14 \%$ in the $\mathrm{NC}$ cohort, whereas only $7 \%$ of people with ID aged $65+$ years appear in the health data sets compared with $34 \%$ of the NC cohort. A higher proportion of males with ID and a lower proportion of females with ID used health services compared with people without ID. People with ID were more likely to live in inner and outer regional, remote and very remote areas whereas a higher proportion of people in the NC cohort lived in major cities.

When examining mental health hospital admissions, and differences between the two cohorts, the rate of mental health admissions was not particularly disparate: $9 \%$ of the ID cohort had at least one mental health-related hospital admission compared with $10 \%$ of the NC cohort. Table 3 shows the mental health admissions of people in both cohorts in public and private hospitals. Note that $88 \%$ of admissions of people with ID were to public hospitals whereas people in the NC cohort had similar admission rates in public and private hospitals $(49 \%$ and
$50 \%$, respectively). As table 2 indicates, age, sex, socioeconomic disadvantage and remoteness differ between the two cohorts. Using logistic regression to adjust for these factors, the odds were 6.5 times greater for people in the ID cohort to be admitted to public hospitals than people in the NC cohort.

The length of stay (LOS) in psychiatric units differs vastly between public and private hospitals as $80 \%$ of stays in private hospitals are 1 day only. The hospital APDC data for same day admissions include procedures that are generally day treatments and programme, such as maintenance electroconvulsive therapy. Correspondingly, as people in the ID cohort are more likely to be admitted to a public hospital, a higher proportion had longer stays in psychiatric wards compared with the NC cohort. The median LOS for admissions among the ID cohort was 4 days (IQR 1-15 days). The median LOS for admissions among the NC cohort was 1 day (IQR 1-9 days) (not shown in table). Adjusting for age, sex, socioeconomic disadvantage and remoteness, the odds for admissions among the ID cohort were half as likely to be 1 day admissions compared with the NC cohort. Analyses using these data should therefore control for public versus private admissions so that LOS attributable to hospital type is disentangled from membership in the ID or NC cohort. When looking at the days spent in a psychiatric unit at a person level, individuals in the ID cohort had a median LOS of 33 days (IQR 7-129 days) and the NC cohort had a median LOS of 17 days (IQR 4-48 days). We have previously shown that the presence of ID is significantly associated with public emergency department presentations and, controlling for hospital type, psychiatric readmissions after the first psychiatric admission. ${ }^{13}$

\section{Mortality}

People with ID were more likely to die at a younger age compared with people in the NC cohort. More than half of the ID cohort in the mortality data set died between 0 and 64 years of age (65\%) compared with $16 \%$ of the $\mathrm{NC}$ cohort. (Note that all individuals who appear in the mortality data set are aged as of the date of death.) Our published research revealed that adults with ID experience premature mortality and an over-representation of potentially avoidable deaths, defined as deaths that can

Table 3 Mental health-related admissions to private and public hospitals for people with and without ID 2001-2015

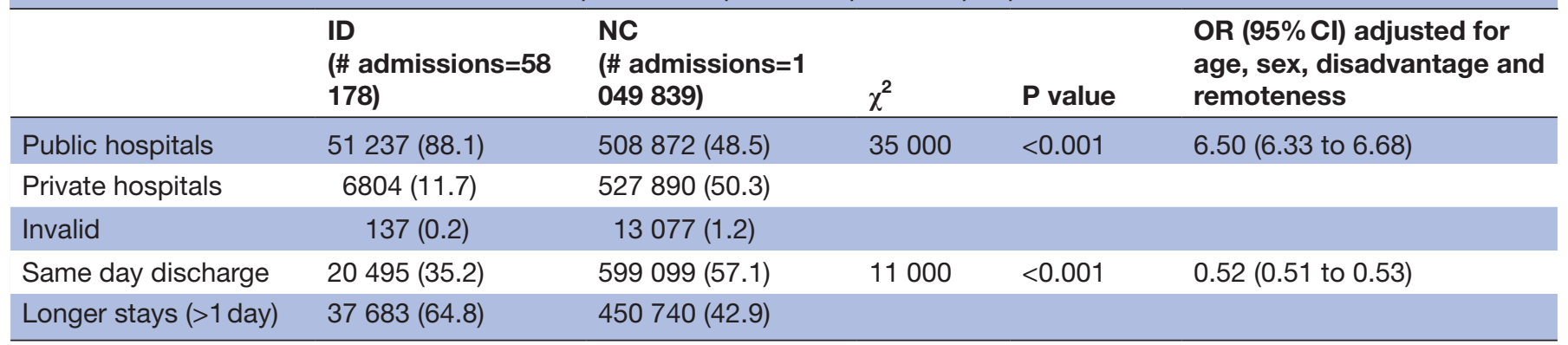

ID, intellectual disability; NC, neuropsychiatric and developmental disorders comparison cohort. 
be prevented through early intervention and appropriate healthcare, for example, death due to respiratory causes. ${ }^{6}$

\section{Corrective services}

Among those individuals in our sample who had been incarcerated, those with ID were younger compared with those in the NC cohort (based on age in 2015). People with ID were also younger at the date of first incarceration (median age of 21.1 (IQR 18.9-26.5) years compared with 24.5 (IQR 19.8-35.5) years for the NC cohort). Over twice the proportion of people with ID aged between 0 and 24 years appeared in the corrective services dataset compared with the NC cohort $(17.9 \%$ vs $7.1 \%)$. Males and females were equally represented in the two groups, and there was no particular difference in socioeconomic disadvantage between the groups. Approximately half of both cohorts were in the lowest 2 quintiles of the socioeconomic disadvantage index.

\section{Strengths and limitations}

The main strengths of this study include the size of the cohort and the comprehensive nature of the data across a wide range of domains to profile the health and service use of people with ID compared with those with neuropsychiatric conditions. This cohort is one of the largest cohorts of people with ID internationally. Other large international record linkage studies including health services for people with ID are mainly based in the UK, ${ }^{17}$ Sweden ${ }^{18}$ and Canada. ${ }^{19}{ }^{20}$ However, most linked administrative health data studies rely on only a few data sources and hence may underestimate the ID population. Our study is unique in its ability to include diagnostic information from multiple sources including criminal justice, disability services and disability support in public schools. The Manitoba Population Research Data Repository in Canada $^{21}$ is another example of linked data from multiple sources including health, education, justice and social services.

Patterns of service use can be examined in different service systems (health, disability, Corrective Services NSW, targeted specialist support in public schools, NSW Public Guardian and NSW Ombudsman). Within the health service system, it is possible to examine different specific components of the system, that is, inpatient, emergency adult services, ambulatory mental health services and how these components interact. The health data sets include variables that allow us to explore the costs of service use. The neuropsychiatric comparison cohort allows comparisons of the physical health, mental health, service use profiles and mortality of people with ID and those with other neuropsychiatric disorders. Key strengths of record linkage research are the minimisation of particular types of selection bias (ie, relating to differential likelihood of refusal or inability to consent to research) and minimisation of attrition compared with other types of longitudinal research where large numbers and particular types of participants are lost to follow-up over time. In addition, record linkage studies avoid problems of observer/interviewer and recall biases.

As with most administrative data sets, the included linked data sets do not contain detailed clinical information and as such have limitations. Some variables that would add valuable information to our models, for example, relating to severity of disability or measures of adaptive behaviour, are not available in the data sets. This may increase the chances of potentially unmeasured confounding variables in our models. Available variables may not capture precisely what is desired and may be too crude a measurement (eg, location measures are broad). In order to receive a disability-related support or service in non-health jurisdictions, there must be independent verification and documentation of the formal diagnosis provided by an appropriately qualified and skilled health professional. However, as a limitation of administrative data sets, we cannot verify the accuracy of the diagnostic data. Another limitation is the duration of data availability and that the data sets do not overlap exactly in time. Record linkage can sometimes erroneously make false-positive links or fail to link when a true link exists (false negative). However, the $\mathrm{CHeReL}$ estimated the false-positive rate for this linkage to be $0.5 \%$. The cohort only includes people with ID who are identified based on the criteria above. Therefore, it is likely that people with milder ID and who are not receiving disability services or do not have an ICD-10 code in their health record are under-represented in this cohort. However, our cohort with ID represents $1.13 \%$ of the NSW population, which is similar to the prevalence rate of ID in the general population $^{34}$ and Australian demographics are similar in most states and territories ${ }^{16}$ so that the results of our analyses will give good insight into the health profiles of service users with ID in Australia. In addition, our cohort with ID includes people identified from Corrective Services NSW who may have not been identified elsewhere. Other studies have shown that a significant number of people in the criminal justice system with an IQ score of two or more SD below the mean are not diagnosed until they are assessed in prison. ${ }^{8}$

The majority of people with a mental illness consult a general practitioner in the first instance,${ }^{22}$ and our linked data set does not include primary health services and most private health services. Therefore, our NC cohort is biased towards acute care and ambulatory mental healthcare and we miss the proportion of people who never had a hospital admission or ambulatory mental health visit.

Linked administrative data provide a rich source of information that can be used to inform policy and services. They can further be used to monitor and evaluate changes in services or systems, for example, the implementation of the Australian National Disability Insurance Scheme. It should be noted that considerable time and resources are required for large data linkage studies. Ethics approval from multiple committees in addition to data custodian approval for all linked data sets, the actual linkage process and subsequent data cleaning can take 2 
to 3 years before data analysis can commence. Substantial costs are associated with linkage, storage of data and manpower. Nevertheless, once the data set is available, it is a powerful resource that can result in multiple influential outputs.

\section{COLLABORATION}

Access to the data and analytical files is permitted subject to the approval of human research ethics committees and data custodians. Researchers interested in collaboration should contact the primary investigator (j.trollor@ unsw.edu.au) with their expression of interest. A full list of publications and further information can be found at https://3dn.unsw.edu.au/project/national-healthmedical-research-council-partnerships-better-healthproject-improving-mental

\section{Author affiliations}

${ }^{1}$ Department of Developmental Disability Neuropsychiatry, UNSW, Sydney, New South Wales, Australia

${ }^{2}$ Centre for Healthy Brain Ageing, UNSW, Sydney, New South Wales, Australia ${ }^{3}$ Intellectual Disability Behaviour Support Program, School of Social Sciences, UNSW, Sydney, New South Wales, Australia

${ }^{4}$ Forensic Mental Health, School of Psychiatry, UNSW, Sydney, New South Wales, Australia

${ }^{5}$ Justice Health and Forensic Mental Health Network, Matraville, New South Wales, Australia

${ }^{6}$ Centre for Disability Research and Policy, Faculty of Health Sciences, University of Sydney, Sydney, New South Wales, Australia

${ }^{7}$ Corrective Services-New South Wales, Department of Justice, Sydney, New South Wales, Australia

${ }^{8}$ School of Social Sciences, Faculty of Arts and Social Sciences, UNSW, Syndey, New South Wales, Australia

${ }^{9}$ Intellectual Disability Network, New South Wales Agency for Clinical Innovation, Sydney, New South Wales, Australia

${ }^{10}$ InforMH, Health System Information and Performance Reporting Branch, NSW Ministry of Health, Sydney, New South Wales, Australia

${ }^{11}$ School of Psychiatry, Sydney Medical School, University of Sydney, Sydney, New

South Wales, Australia

${ }^{12}$ Mental Health Review Tribunal, Gladesville, New South Wales, Australia

${ }^{13}$ Department of Education, Sydney, New South Wales, Australia

${ }^{14}$ NSW Ombudsman, Sydney, New South Wales, Australia

Acknowledgements We would like to acknowledge all investigators and partner organisations contributing to the project: Cls: Julian Trollor, Eric Emerson, Rhoshel Lenroot, Karen Fisher, Kimberlie Dean, Leanne Dowse. Als: Eileen Baldry, Tony Florio, Grant Sara, Phillip Snoyman, Les White. Project staff and students: Preeyaporn Srasuebkul, Erin Whittle, Simone Reppermund, Snow Lee, Bronwyn Newman, Theresa Heintze. Partner organisations: Agency for Clinical InnovationIntellectual Disability Network, NSW Department of Family and Community Services-Ageing, Disability and Home Care, NSW Department of Education, NSW Department of Justice - Corrective Services NSW, NSW Ministry of HealthJustice Health and Forensic Mental Health Network, Mental Health Commission of NSW, NSW Ministry of Health-Mental Health and Drug and Alcohol Office, NSW Ministry of Health—InforMH, Mental Health Review Tribunal, Council for Intellectual Disability, Inclusion Australia, National Disability Services, NSW Office of the Public Guardian, NSW Ombudsman.

Contributors JT conceived and designed the study. KD, MS, EE, PhS, EB, LD, TS, GS, AJ, KM, MC and TF participated in the conceptual design of the study. SR, PrS, TH and JT drafted the manuscript. TH performed the analyses. PrS provided statistical support. RR provided expertise about health economics. All authors critically revised the manuscript and contributed to interpretation of the data. All authors read and approved the final version of the manuscript.

Funding The project is supported by a National Health and Medical Research Council Australia Partnerships for Better Health grant (ID: APP1056128; Title: Improving the Mental Health Outcomes of People with an Intellectual Disability).
Competing interests None declared.

Patient consent for publication Not required.

Ethics approval Ethical approval was obtained from the NSW Population and Health Services Research Ethics Committee (AU RED Study Reference Number: HREC/13/CIPHS/7; CINSW Reference Number: 2013/02/446) and access to the data sets was granted by relevant data custodians.

Provenance and peer review Not commissioned; externally peer reviewed.

Data availability statement Data may be obtained from a third party and are not publicly available.

Open access This is an open access article distributed in accordance with the Creative Commons Attribution Non Commercial (CC BY-NC 4.0) license, which permits others to distribute, remix, adapt, build upon this work non-commercially, and license their derivative works on different terms, provided the original work is properly cited, appropriate credit is given, any changes made indicated, and the use is non-commercial. See: http://creativecommons.org/licenses/by-nc/4.0/.

\section{ORCID iDs}

Grant Sara http://orcid.org/0000-0002-3762-1711

Julian Trollor http://orcid.org/0000-0002-7685-2977

\section{REFERENCES}

1. American Psychiatric Association. Diagnostic and statistical manual of mental disorders. 5th edn. Washington, DC: American Psychiatric Association, 2013.

2. World Health Organization. International statistical classification of diseases and related health problems (11th revision). retrieved from, 2018. Available: https://icd.who.int/browse11/l-m/en

3. Leonard $\mathrm{H}$, Petterson B, Bower $\mathrm{C}$, et al. Prevalence of intellectual disability in Western Australia. Paediatr Perinat Epidemiol 2003;17:58-67.

4. Maulik PK, Mascarenhas MN, Mathers CD, et al. Prevalence of intellectual disability: a meta-analysis of population-based studies. Res Dev Disabil 2011;32:419-36.

5. Cooper S-A, McLean G, Guthrie B, et al. Multiple physical and mental health comorbidity in adults with intellectual disabilities: population-based cross-sectional analysis. BMC Fam Pract 2015;16:110.

6. Trollor J, Srasuebkul P, Xu H, et al. Cause of death and potentially avoidable deaths in Australian adults with intellectual disability using retrospective linked data. BMJ Open 2017;7:e013489.

7. Whittle EL, Fisher KR, Reppermund S, et al. Barriers and Enablers to accessing mental health services for people with intellectual disability: a scoping review. J Ment Health Res Intellect Disabil 2018;11:69-102.

8. Baldry E, Clarence M, Dowse L, et al. Reducing vulnerability to harm in adults with cognitive disabilities in the Australian criminal justice system. J Policy Pract Intellect Disabil 2013;10:222-9.

9. Einfeld SL, Ellis LA, Emerson E. Comorbidity of intellectual disability and mental disorder in children and adolescents: a systematic review. J Intellect Dev Disabil 2011;36:137-43.

10. Dew A, Dowse L, Athanassiou U, et al. Current representation of people with intellectual disability in Australian mental health policy: the need for inclusive policy development. J Policy Pract Intellect Disabil 2018;15:136-44

11. Reppermund S, Dowse L, Dew A, et al. Representation of people with intellectual disability in Australian mental health policy. Aust N Z J Psychiatry 2018;52:618-9.

12. Florio T, Trollor J. Mortality among a cohort of persons with an intellectual disability in New South Wales, Australia. J Appl Res Intellect Disabil 2015;28:383-93.

13. Li X, Srasuebkul P, Reppermund S, et al. Emergency department presentation and readmission after index psychiatric admission: a data linkage study. BMJ Open 2018;8:e018613.

14. Reppermund S, Srasuebkul P, Heintze T, et al. Cohort profile: a data linkage cohort to examine health service profiles of people with intellectual disability in New South Wales, Australia. BMJ Open 2017;7:e015627.

15. Australian Bureau of Statistics. Australian Demographic Statistics. Catalogue number 3101.0. Canberra: Commonwealth of Australia, 2015.

16. Australian Bureau of Statistics. Socio-Economic Indexes for Areas (SEIFA). 2011. ABS catalogue No. 2033.0.55.001. Canberra: Commonwealth of Australia, 2013. 
17. Glover G, Williams R, Tompkins G, et al. An observational study of the use of acute hospital care by people with intellectual disabilities in England. J Intellect Disabil Res 2019;63:85-99.

18. Axmon A, Björne $P$, Nylander $L$, et al. Psychiatric diagnoses in older people with intellectual disability in comparison with the general population: a register study. Epidemiol Psychiatr Sci 2018;27:479-91.

19. Balogh R, Lin E, Dobranowski K, et al. All-Cause, 30-day readmissions among persons with intellectual and developmental disabilities and mental illness. Psychiatr Serv 2018;69:353-7.
20. Shooshtari S, Martens PJ, Burchill CA, et al. Prevalence of depression and dementia among adults with developmental disabilities in Manitoba, Canada. Int J Family Med 2011;2011:1-9.

21. University of Manitoba. Manitoba Population Research Data Repository - Overview, 2019. Available: http://www.umanitoba.ca/ faculties/health_sciences/medicine/units/chs/departmental_units/ mchp/resources/repository/index.html

22. Slade T, Johnston A, Teeson M, et al. The mental health of Australians 2. Report on the 2007 national survey of mental health and wellbeing. Canberra: Department of Health and Ageing, 2009. 